Viso - Cadernos de estética aplicada Revista eletrônica de estética

ISSN 1981-4062

$\mathrm{N}^{\circ} 2$, mai-ago/2007

http://www.revistaviso.com.br/

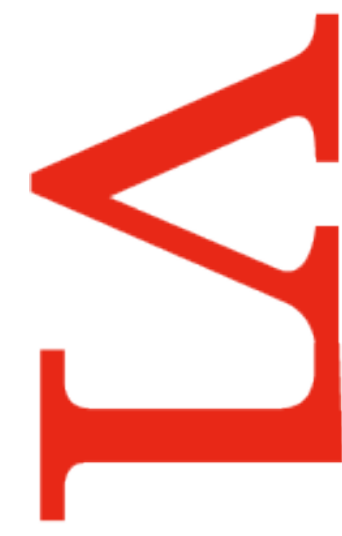

\title{
Pisando em putas: Notas sobre o vigor contemporâneo do fascismo tupiniquim \\ Pedro Amaral
}




\section{RESUMO}

Pisando em putas:

Notas sobre o vigor contemporâneo do fascismo tupiniquim

O artigo analisa fatos recentes relacionados ao combate à prostituição no Brasil, baseado em lei incoerente e ultrapassada, para, inspirado pela leitura de Mille Plateaux, de Deleuze e Guatarri, apontar a perigosa vitalidade do desejo fascista na sociedade brasileira contemporânea.

Palavras-chave: prostituição - fascismo - violência - Mil Platôs

\section{ABSTRACT}

Trampling on prostitutes:

Notes about the contemporary vitality of Brazilian Fascism

This paper, inspired by the reading of Deleuze \& Guattari's Milles Plateaux, examines recent events related to the fight against prostitution in Brazil (which is based, we assume, on an incoherent, outdated law) to point at the dangerous vitality of fascist desire in contemporary Brazilian society.

Keywords: prostitution - Fascism - violence - Mille Plateaux 


\section{AMARAL, P. "Pisando em putas: Notas sobre o vigor contemporâneo do fascismo tupiniquim". In: Viso: Cadernos de estética aplicada, v. I, n. 2 (mai-ago/2007), pp. 38-46.}

DOI: $10.22409 / 1981-4062 / \mathrm{V} 2 \mathrm{i} / 39$

Aprovado: 17.07.2007. Publicado: 12.08.2007.

(C) 2007 Pedro Amaral. Esse documento é distribuído nos termos da licença Creative Commons Atribuição-NãoComercial 4.0 Internacional (CC-BY-NC), que permite, exceto para fins comerciais, copiar e redistribuir o material em qualquer formato ou meio, bem como remixá-lo, transformá-lo ou criar a partir dele, desde que seja dado o devido crédito e indicada a licença sob a qual ele foi originalmente publicado.

Licença: http://creativecommons.org/licenses/by-nc/4.0/deed.pt_BR

Accepted: 17.07.2007. Published: 12.08.2007.

(C) 2007 Pedro Amaral. This document is distributed under the terms of a Creative Commons Attribution-NonCommercial 4.0 International license (CC-BY-NC) which allows, except for commercial purposes, to copy and redistribute the material in any medium or format and to remix, transform, and build upon the material, provided the original work is properly cited and states its license.

License: http://creativecommons.org/licenses/by-nc/4.0/ 


\section{De Madri a Copacabana}

O longa-metragem Princesas, do espanhol Fernando León de Aranoa, recentemente exibido no Rio de Janeiro, retrata a amizade entre duas prostitutas, a espanhola Caye (vivida por Candela Peña) e a dominicana Zulema (Micaela Nevárez), em sua batalha cotidiana pelas ruas de Madri. Caye, como a maior parte de suas colegas de profissão, procura ocultar o que faz de sua família - uma família de classe-média como tantas, ordinária e banal -, e quando informa ao namorado, já no primeiro encontro, "yo soy puta" (como quem arrisca livrar-se do peso de um segredo), este apenas ri, incrédulo. É ela quem protagoniza uma das cenas de maior intensidade dramática do filme, quando, durante um jantar romântico em um restaurante, é reconhecida por um cliente reunido com amigos numa mesa vizinha. Constrangida pelos olhares e risos maliciosos daqueles homens, ela é ainda seguida até o banheiro pelo playboy, e acaba, diante de uma gorda oferta de euros, aceitando praticar um fellatio, enquanto lágrimas lhe escorrem pelo rosto e o namorado a espera à mesa. A exuberante Zulema, por sua vez, é seguidamente espancada por um escroque que a chantageia com a oferta ilusória de um visto de trabalho, teme diariamente as investidas da polícia na praça onde faz ponto, e sofre o preconceito das prostitutas nativas com quem disputa espaço (por ser imigrante), e dos compatriotas que Ihe alugam a cama (por ser puta). Descobrindo-se portadora do vírus HIV, e saudosa de seu filho, resolve por fim regressar ao Caribe natal.

Não se trata, como se vê, de nenhuma comédia, e se o material publicitário destaca, na obra, "o mesmo estilo de Almodóvar", isso talvez se deva ao fato de Aranoa - cineasta de talento bem mais modesto que o de seu renomado compatriota - também voltar seu olhar para a solidariedade feminina, com sensibilidade para retirar da situação de ninguneo, isto é, de completa negação, personagens marginalizadas como as profissionais do sexo. Embora a opção pelo drama favoreça a reprodução da tradicional visão vitimizadora das prostitutas, o cruzamento entre as trajetórias de Caye e Zulema permite uma abordagem ampla do tema, que considere fatores como a imigração SulNorte, a pobreza, mas não ignore o desejo, a iniciativa individual. Um filme, em todo caso, não é uma tese...

A exibição no Brasil deste pequeno filme de roteiro esquálido, desigual, mas com trunfos como a boa atuação de Candela Peña, e momentos marcantes como a cena citada e o encerramento, foi sem dúvida oportuna e salutar. Isto porque hoje, no país, em que pesem o sucesso de vendas de livros com relatos de ex-garotas de programa e a visibilidade que o movimento de prostitutas (em luta pela regulamentação da profissão) vem obtendo por meio da grife $D a s p u^{1}$, o cotidiano das mulheres - e homens - que 
trabalham com sexo, os pobres sobretudo, continua a ser marcado por toda sorte de abuso e violência, o que dá mostra da vitalidade das paixões fascistas numa sociedade em que, como bem diagnosticou Chico Buarque, "o medo da violência se transformou em repúdio não só ao chamado marginal, mas aos pobres em geral, ao motoboy, ao sujeito que tem carro velho, ao sujeito que anda mal vestido". ${ }^{2}$

Assim, uma ação recente de combate ao crime empreendida pela polícia paulista levou à cadeia centenas de acusados de práticas ilícitas, efetuou o fechamento de dezenas de oficinas de desmanche de carros roubados... e, de quebra, resultou na detenção de prostitutas que trabalhavam na Praça da República, na capital.

Protesto nenhum da chamada sociedade civil.

Enquanto isso, no Rio de Janeiro, sob silêncio igualmente eloqüente, o bairro mais famoso da cidade ("Um bom lugar / à beira-mar...") tem sido palco da Operação Copabacana, implementada pelo governo do Estado, que visa a limpar a região de elementos indesejáveis - no caso, prostitutas e travestis que fazem ponto na orla - como forma de "coibir uma série de delitos que têm acompanhado a atividade, como roubo, tráfico de drogas e prostituição infantil" ${ }^{3}$. Os préstimos das autoridades fluminenses à burguesia local, ciosa do valor de suas propriedades, traduzem-se na realização de detenções de pessoas que, na maior parte dos casos, são posteriormente devolvidas à liberdade, uma vez verificados seus antecedentes e comprovada sua inocência. Trata-se, evidentemente, de inversão - cada vez mais difundida nos dias de correm, diga-se de passagem - do princípio constitucional da presunção de inocência ${ }^{4}$, praticada simultaneamente aos crimes de abuso de autoridade e constrangimento ilegal. É a micro-gestão de pequenos medos governando a ação do aparelho estatal e enquadrando, em primeiro lugar - e ao arrepio da lei -, os alvos preferenciais de sempre, aqueles que o próprio Estado marginaliza.

\section{Promovendo a violência onomástica}

O combate à prostituição, terreno privilegiado do ancestral empenho estatal pelo domínio dos corpos, tem propiciado, nestes tempos que consagram como nunca o valor de troca do sexo, uma repetição ad infinitum de episódios tão grotescos e ridículos como aqueles do âmbito da operação carioca. ${ }^{5}$ A lei brasileira fornece o mote do espetáculo, ao estabelecer que a prática da prostituição não é crime, mas a sua exploração, sim. Proposição já de si absurda, incoerente, que se torna tanto menos defensável na medida em que sua implementação se faz de modo seletivo e arbitrário. Assim, no período prénatalino de 2005, o Ministério Público do Rio Grande do Norte, na pessoa do promotor Evaldo Alves Barbosa, ofertou denúncia "em desfavor" de pessoas que trabalhavam numa casa noturna da capital, sustentando que elas deveriam ser responsabilizadas penalmente por crimes de "turismo sexual, prostituição, tráfico interno para fins de prostituição, entre outros crimes contra os costumes". ${ }^{6}$ Interessante notar, aquilo que o 
cioso promotor denuncia como "formação de quadrilha" (respaldado, é verdade, pelo confuso Código Penal) não se assemelha, a julgar por seu próprio texto, a nada além de uma prestação de serviços como tantas, em que é mantida estrutura adequada à realização do negócio, pessoas são responsáveis pelo alojamento, outras pelo transporte, outras pelo serviço propriamente dito (os "encontros de natureza sexual"), todas remuneradas e "agindo de forma consciente e voluntária, em unidade de desígnios e comunhão de vontades", como relata o denunciante com involuntário lirismo.

É também significativo o fato de as prostitutas - supostas vítimas de exploradores - não serem ouvidas em momento algum pelo promotor, não opinarem: são privadas do poder de agência, destituídas do lugar de enunciação, como se diz em sociologia. O mais significativo nessa operação, contudo, é o seguinte: de modo a manter em sigilo, portanto preservar, a identidade dos desfavorecidos, seus nomes são reduzidos a meras abreviaturas, surgindo assim A.C., C.C.P.A., L.P. da S. (aqui, pecou-se por inconfidência: o nome só pode ser 'da Silva', aliás sinônimo, no Brasil, de gente do povo), F.N.F., A. T. de C.J... Ora, sabemos que o terreno das prostitutas é o da multiplicidade: multiplicidade de parceiros, de práticas, de fantasias, de lugares de trabalho muitas vezes, a que corresponde uma pluralidade de personas (a malvada, a boazinha, a mãe, a filhinha, a enfermeira), refletida, por sua vez, em nomes plurais. Assim, Rozelma é também Babi, é Samantha, e é Cibele. Fabíola é Maya, é Lili, é Clara ou Janete; e assim por diante. ${ }^{7}$

Curioso que o empenho em preservar identidades resulte justamente na destruição da marca da identidade, qual seja, o nome - destruição que poderíamos chamar de violência onomástica; e que, de modo similar, o objetivo de preservar a integridade de alguém implique justamente desconsiderá-lo como sujeito. Significativa, ainda, a obsessão em conter a multiplicidade, portanto o movimento, levando o aparelho repressivo (em que aqui se vê convertido o MP) a práticas como o monitoramento de conversações telefônicas, tão próxima da perversão. ${ }^{8}$

\section{As 'tias de Marlow'}

No romance $O$ coração das trevas, de Joseph Contrad, o capitão Kurtz, incumbido pela Sociedade Internacional pela Supressão dos Costumes Bárbaros de elaborar um relatório, não elabora relatório algum, e se vê por fim confundido com os 'bárbaros' que Ihe coubera ajudar a suprimir. Se o projeto da tal Sociedade parece chafurdar no horror da selva africana, é preciso notar que o desejo que a impele continua a se propagar, de modo difuso, subterrâneo, quase imperceptível. Penso na fala da amorosa tia de Marlow, que recebe o sobrinho para uma xícara de chá pouco antes de seu embarque para a África e, entusiasmada com o que vinha lendo na imprensa, o exorta a "arrancar aqueles milhares de ignorantes de seus horríveis costumes". ${ }^{9}$ Ou seja: esse desejo que pede a eliminação, pela força se necessário, dos elementos indesejáveis, com vistas a manter a ordem hierárquica vigente, e que aqui denominamos fascismo, quando não logra 
avançar por meio dos grandes empreendimentos, propaga-se por intermédio das 'tias', que o nutrem com seus pequenos, cotidianos investimentos desejantes.

Deleuze e Guatarri advertem que

[...] é uma potência micro-política ou molecular que torna o fascismo perigoso, porque se trata de um movimento de massa: um corpo canceroso mais que um organismo totalitário. $^{10}$

Os autores anotam ainda - e ressalto a relevância dessa reflexão para nós que aqui vivemos nos dias que correm - que

A administração de uma grande segurança molar [i.e., macro-política] tem por correlata toda uma micro-gestão de pequenos medos, toda uma insegurança molecular [i.e., micro-política] permanente. ${ }^{11}$

Não se trata aqui, portanto, tão-somente do fascismo personificado por Hitler e Mussolini, mas do fascismo como agenciamento coletivo de desejo, que se dá não apenas em momentos históricos grandiosos, mas no dia-a-dia, fazendo, como diz Foucault, "a amena tirania de nossas vidas cotidianas" ${ }^{\prime 2}$, na medida em que nos faz amar o poder e nos envolve em sua lógica paranóica e totalizante.

Quando os batavos eram repelidos da costa brasileira, Spinoza relatava - com pavor não destituído, talvez, de alguma nota de erotismo - um pesadelo recorrente em que um enorme canibal negro brasileiro assomava em seu quarto, no meio da noite. Evocando imagem semelhante, há dois anos, uma 'tia de Marlow' escrevia, em sua coluna num jornal carioca: "Estamos salpicados de favelas, de onde descem hordas de vagabundos de bermuda para pescar cidadãos como num parque temático". ${ }^{13}$ Aqui, a clássica estruturação do discurso fascista por oposições hierárquicas estanques: de um lado a favela e seus "vagabundos de bermuda", difusos numa horda; de outro, no asfalto, os cidadãos de bem. E a eliminação do outro, do elemento perturbador, não apenas figurando como desejo subjacente ao discurso, mas se realizando no próprio discurso, que o estigmatiza, o desumaniza, como na fala do colonizador sobre o colonizado, tão bem analisada por Frantz Fanon. ${ }^{14}$ Por fim, a imagem fantástica de um parque temático no qual as pessoas de bem se vêem acuadas pelos seus algozes, configurando um cenário de pesadelo como aquele que tirava o sono do filósofo holandês.

\section{A brutalidade integrada}

Na madrugada do último 24 de junho, a empregada doméstica Sirley Dias de Carvalho Pinto aguardava sua condução num ponto de ônibus na Barra da Tijuca, Rio de Janeiro, quando foi atacada por cinco valentões de classe-média alta ${ }^{15}$, que a espancaram e roubaram-lhe a bolsa. Na delegacia, os criminosos teriam alegado haver confundido a vítima com uma prostituta. Investigações posteriormente indicaram, com efeito, que o 
grupo tinha o hábito de dispensar igual tratamento a profissionais do sexo, havendo inclusive agredido uma prostituta naquela mesma noite. O crime e a alegação absurda relembram, como bem salientou a imprensa, o caso ocorrido em Brasília em 20 de abril de 1997, quando o índio Galdino Jesus dos Santos foi queimado vivo por outro grupo de cinco arruaceiros bem-nascidos ${ }^{16}$, os quais argumentaram em sua defesa havê-lo confundido com um mendigo.

Se semelhantes atos despertam manifestações de repúdio mais que justificadas, não deveriam, contudo, ser recebidos com surpresa: afinal, consistem tão-só em tradução mais tosca e brutal de gestos cotidianos de intolerância, dispersos pelos mais diversos âmbitos da vida brasileira. É menos significativo, em suma, o fato de a alegação dos agressores de Sirley não ter sido aceita como justificativa do que o fato de ela haver sido formulada, e ainda pronunciada: é aí que o gesto individual de estupidez - sem por isso deixar de sê-lo - revela-se também uma construção social. Um produto da civilização brasileira em tempos de paranóia.

\section{* Pedro Amaral é doutorando em letras pela PUC/RJ.}

${ }^{1}$ Que, por sinal, apresentou um desfile na pré-estréia carioca de Princesas, no Espaço de Cinema.

${ }^{2}$ Entrevista concedida à Folha de São Paulo em 26/09/2004.

3 "Prostitutas são novo alvo de Operação Copabacana". O Globo, 07/05/2007.

4"Ninguém será considerado culpado até o trânsito em julgado de sentença penal condenatória" (CF, art. $\left.5^{\circ}, \S L V I I\right)$.

${ }^{5}$ Vale lembrar, em 2005 o jornal O Globo empreendia, para deleite de boa parte de seus leitores, jornada cívica contra o turismo sexual que teve como alvo declarado os 'rufiões' da orla de Copacabana - causando, claro, grandes transtornos e algumas prisões. Desejaria a família Marinho repreender os profissionais do sexo que não anunciam nos classificados do seu jornal? Ou restringir a exploração comercial do sexo ao horário nobre de seu canal de TV? São questões que o episódio inspira. Seria injusto, talvez, associar o poderoso grupo de mídia a deploráveis práticas monopolistas...

${ }^{6}$ Fonte: http://www.mp.rn.gov.br/caops/caopjp/pecas. Acessado em 24/05/2007.

7"Prostituta é muito rotativa, você vai muito de um lugar para outro", afirma Doroth de Castro Ferreira, em entrevista ao livro As meninas da Daspu, organizado por Anna Marina Barbará (Teresópolis: Novas Idéias, 2007, p. 32).

8 "Ligações telefônicas monitoradas durante a investigação comprovam como se procedia à negociação dos 'programas' com fins sexuais", "Chegava-se a reservar suítes em motéis para que se efetivassem os encontros de natureza sexual, como pode ser comprovado nas ligações efetuadas no dia [sic] 28 de outubro e 08 de novembro (interceptações n's 12, 13 e 14)".

${ }^{9}$ CONRAD, J. Coração das trevas. São Paulo: Nova Alexandria, 2001, p. 27.

10 DeleuZE, G.; GuATTARI, F. Mille Plateaux. Paris: Les Editions de Minuit, 1980. Tradução minha. 
${ }^{11}$ Ibidem, p. 263.

${ }^{12}$ FOUCAULT, M. [1977]. "Introdução à vida não-fascista". In: Comunicação\&politica, v. 24, n. 2. Rio de Janeiro: CEBELA, 2006.

13 JABOR, A. "PRJ - Partido do Rio de Janeiro". O Globo, 15/03/2005.

${ }^{14}$ Cf. FANON, F. [1961]. The wretched of the Earth. Middlesex: Penguin Books, 1967.

${ }^{15}$ Nomeadamente Felippe de Macedo Nery Neto, Júlio Junqueira, Leonardo Andrade, Rodrigo Bassalo e Rubens Arruda - que não foi indiciado até o momento.

${ }^{16}$ A saber: Antônio Novely Villanova, Eron Chaves de Oliveira, Max Rogério Alves, Tomás Oliveira e Gutemberg de Almeida (então menor de idade). 